\title{
New material perspective for endocrown restorations: effects on mechanical performance and fracture behavior
}

José Augusto SEDREZ-PORTO(a) Eliseu Aldrighi MÜNCHOW(b) Lisia Lorea VALENTE(a) (iD Maximiliano Sergio CENCI(a) Tatiana PEREIRA-CENCI(a) iD

(a) Graduate Program in Dentistry, Federal University of Pelotas, Pelotas-RS, Rua Gonçalves Chaves 457, 96015560, Brazil.

(b) Department of Dentistry, Health Science Institute, Federal University of Juiz de Fora, Governador Valadares-MG, Av. Raimundo Monteiro Rezende, 35010177, Brazil.

Declaration of Interests: The authors certify that they have no commercial or associative interest that represents a conflict of interest in connection with the manuscript.

Corresponding Author:

Tatiana Pereira Cenci

E-mail: tatiana.dds@gmail.com

hitps://doi.org/10.1590/1807-3107bor-2019.vol33.0012

Submitted: May 14, 2018

Accepted for publication: November 26, 2018

Last revision: January 10, 2019
Abstract: The aim of this study was to investigate the mechanical performance and the fracture behavior of endocrown restorations prepared using distinct restorative materials. A total of 42 sound molars with similar crown size and shape were cut at $2 \mathrm{~mm}$ above the cementoenamel junction and endodontically treated. They were categorized according to the restorative material used to fabricate endocrown restorations $(\mathrm{n}=7)$, namely, conventional composite (Filtek ${ }^{\mathrm{TM}}$ Z350 XT), bulk fill composite (Filtek ${ }^{\mathrm{TM}}$ Bulk Fill), conventional composite modeled using resin adhesives (SBMP: Scotchbond ${ }^{\mathrm{TM}}$ Multipurpose Adhesive; or SBU: Scotchbond ${ }^{\mathrm{TM}}$ Universal Adhesive), and IPS e.max lithium disilicate (Ivoclar Vivadent; positive control). Unprepared sound teeth were used as negative control. All endocrowns were bonded using a self-adhesive cement (Rely- $X^{\mathrm{TM}} \mathrm{U} 200$ ). The teeth were submitted to fatigue (Byocycle) and fracture (EMIC DL500) testing. Load-to-fracture (in $\mathrm{N}$ ) and work-of-fracture $\left(\mathrm{W}_{\mathrm{f}}\right.$, in $\left.\mathrm{J} / \mathrm{m}^{2}\right)$ values were analyzed by ANOVA $(p<0.05)$. The endocrowns did not fracture or de-bond upon fatigue, showing similar load-to-fracture and work-of-fracture values, regardless of the restorative material $(p>0.05)$. The endocrowns fabricated by combining Z350 and SBMP had the least harsh fractures, in contrast to endocrowns prepared using Z350 only, which exhibited an equilibrium between repairable and irrepairable fractures. The e.max endocrowns exhibited more aggressive failures (root fracture) than other groups, resulting in higher rates of irrepairable fractures. In conclusion, dental practitioners may satisfactorily restore severely damaged nonvital teeth using the endocrown technique. Composite endocrowns prepared using resin adhesive as modeler liquid or using bulk fill material may result in less aggressive failures, thus providing a new material perspective for endocrown restorations.

Keywords: Ceramics; Fatigue; Composite Resins; Filtek Bulk Fill; Tooth Fractures.

\section{Introduction}

Tooth rehabilitation may depend on several factors, including but not limited to the professional's understanding of the potentials and limitations 
of the restorative technique, the amount of remaining tooth structure, the presence or absence of endodontic treatment, and the patient's expectations. ${ }^{1,2} \mathrm{~A}$ major concern associated with the rehabilitation of severely damaged teeth is the devolution, as close as possible, of the natural biomechanical characteristics of dental substrates. Notwithstanding, this may never occur completely, especially due to the different stiffness of current dental restoratives compared with dentin. ${ }^{3}$ Some restoratives are stiffer and stronger than dentin, as in the case of dental ceramics and metal-based materials, whereas others, despite exhibiting similar stiffness and toughness properties (e.g., resin composites and glass-fiber posts), may result in a weaker behavior, thus contributing to early wear and failure of the restoration. For several years, the rehabilitation of nonvital teeth has been performed by combining metal-based posts with core materials, followed by placement of ceramic crowns. ${ }^{4}$ In fact, the abovementioned restorative technique has been demonstrated to be effective, ${ }^{5,6}$ although fracture extending to the root was found to be a frequent consequence upon failure, probably due to the high stiffness of that restorative system. ${ }^{78}$ Unfortunately, the complexity of the treatment may increase under this failure condition, resulting in tooth loss. ${ }^{9}$ In the light of this, compliant (i.e., less stiff) materials such as resin composites have been currently considered for restoration of severely damaged nonvital teeth, with an adequate survival rate as well as a considerably lower rate of root fractures when compared with conventional treatments. ${ }^{6,10}$

Currently, rehabilitation of nonvital teeth with less amount of remaining tooth structure and by preserving most of the remaining substrate involves the placement of glass-fiber posts into the largest root canal with the subsequent preparation of a core or final restoration using resin composites. ${ }^{6}$ An alternative available treatment modality that avoids the placement of glass-fiber posts into the root canal is the endocrown restoration, ${ }^{10,11}$ i.e., one single system that is placed into nonvital teeth and anchored to the internal portion of the pulp chamber and at the cavity margins, resulting in both macromechanical (due to the circumferential walls of the pulp chamber) and micromechanical (due to the use of adhesive materials) retention. ${ }^{12}$
Endocrown restorations were initially prepared using glass-ceramics, but due to their greater stiffness and brittleness, fractures extending to the root have also been frequently observed. ${ }^{13,14} \mathrm{~A}$ recent systematic review and meta-analysis regarding endocrown restoration $s^{15}$ demonstrated that endocrowns may perform similarly or better than the conventional treatments using intraradicular posts, direct resin composites, or inlay/onlay restorations. In addition, Rocca et al. ${ }^{16}$ suggested that endocrowns may transmit occlusal forces more homogeneously than the use of intraradicular posts. Not less important, resin composites have been used to prepare endocrown restorations with a more compliant behavior, i.e., with more similar biomechanical characteristics to those of dentin. ${ }^{11,17}$ Nevertheless, the use of resin composites to fabricate large restorations may produce cohesive failures within the body of the material as well as develop a significant amount of polymerization stress, which would contribute to jeopardizing the clinical performance of endocrowns over time.

Recently, two strategies have been described that may be useful to compromise the abovementioned limitations of composite endocrowns, which are the use of less viscous resins as a modeler liquid of composite restorations and the use of new-generation, bulk fill resin composites rather than conventional composites. According to some studies, the cohesive strength of a nanofilled resin composite (Filtek ${ }^{\mathrm{TM}} \mathrm{Z} 350$ XT; 3M ESPE) was significantly improved when the composite was modeled using resin adhesives (i.e., resins with low viscosity) as the modeler liquid of composite restorations, ${ }^{18}$ in addition, the color and translucency properties were more stable over time when the composite was modeled with the resin adhesives..$^{19}$ Polymerization stress would also be less intense within the bulk of the composites containing the modeler liquid, as the presence of this more compliant material, which is generally composed of an unfilled resin, would serve as stress-relieving sites within the body of the restoration. ${ }^{20}$ Regarding the use of bulk fill resin composites, studies have demonstrated their positive effect in reducing the development of polymerization stress, probably due to a more compliant behavior, allowing stress relief..$^{21}$ In addition, bulk fill composites are generally less 
viscous than conventional composites, a fact that would improve cohesiveness within the restoration. To the best of our knowledge, the two abovementioned strategies have never been investigated as potential restorative materials for endocrown restoration.

Therefore, this study was conducted with the following two objectives: (a) to prepare endocrown restorations using distinct restorative materials and (b) to evaluate their mechanical performance and fracture behavior after mechanical aging (fatigue). The hypothesis of this study was that endocrowns fabricated using less viscous resins (modeler liquid) or bulk fill resin composites would exhibit greater mechanical performance than endocrowns prepared using conventional composite or glass ceramic.

\section{Methodology}

A total of 42 sound human mandibular molars were obtained from a Human Teeth Bank (BDH/ Unoesc - Banco de DentesHumanos da Faculdade do Oeste de Santa Catarina; Joaçaba, SC, Brazil) after obtaining approval from the Ethics Committee of the School of Dentistry at the Federal University of Pelotas (Pelotas, RS, Brazil), under the following protocol number: 1.634.774/2016. The teeth were similar in size (i.e., crowns with similar mesiodistal and buccolingual dimensions at the cementoenamel junction) and morphology and were free of restorations and any root canal treatment. The teeth were stored in $0.5 \%$ aqueous chloramine solution at $4^{\circ} \mathrm{C}$ until use (maximum of 3 months). Seven teeth were kept unmodified to serve as negative control (sound tooth group). The remaining 35 teeth (experimental ones) were shaped at the coronal portion with an impression material (Futura AD; Nova DFL, Jacarepaguá, RJ, Brazil) to facilitate the posterior build-up process of the restoration to its original anatomical shape (Figure 1a). Sample size was estimated using a sample size calculator and based on the results of a previous study conducted under similar conditions. ${ }^{22}$

\section{Tooth preparation, endodontic treatment, and group allocation}

The crown of each experimental tooth was sectioned $2.0 \mathrm{~mm}$ above the cementoenamel junction (CEJ). The pulp chamber was then opened using a standardized procedure, and root canals were instrumented using stainless steel K-files nos. 15, 20, 25, and 30 (Dentsply Maillefer, Ballaigues, Switzerland), followed by rotary Ni-Ti instruments (Protaper Universal 21mm SX-F3; Dentsply Maillefer), according to the manufacturer's instructions. Root canals were irrigated between each of the instrumentation using $1 \mathrm{ml}$ of $2.5 \%$ sodium hypochlorite solution. The roots were filled using the warm vertical condensation technique and combining calibrated gutta-percha $\mathrm{f} 2$ and $\mathrm{f} 3$ (Protaper; Dentsply Maillefer) with an endodontic sealer (AHplus, Dentsply Maillefer). The teeth were stored under dark conditions, and after a setting period of $48 \mathrm{~h}$, they were randomly allocated $(n=7)$ according to the restorative materials used as follows:

a. Z350: conventional resin composite $\left(\right.$ Filtek $^{\mathrm{TM}}$ Z350 XT; 3M ESPE);

b. Z350+SBMP: conventional resin composite modeled with the bond component of Adper ${ }^{\mathrm{TM}}$ Scotchbond ${ }^{\mathrm{TM}}$ Multi-Purpose Adhesive (SBMP; 3M ESPE);

c. Z350+SBU: conventional resin composite modeled with Scotchbond ${ }^{\mathrm{TM}}$ Universal Adhesive (SBU; 3M ESPE);

d. Bulk Fill: posterior resin composite for bulk restoration (Filtek ${ }^{\mathrm{TM}}$ Bulk Fill; 3M ESPE);

e. E.max: IPS e.max lithium disilicate (Ivoclar Vivadent, Liechtenstein, Germany).

Details regarding the manufacturer, lot number, and composition information of the materials used to fabricate the endocrowns are shown in Table 1.

\section{Alveolar bone and periodontal ligament simulation}

The alveolar bone and the periodontal ligament that generally surround implanted teeth were simulated by embedding each root into plastic cylinders with a self-cured acrylic resin (Jet Clássico, São Paulo, Brazil) and using a polyether impression material (Impregum Soft, 3M ESPE), respectively. ${ }^{23}$ Briefly, the root surfaces were dipped into melted wax (Lysanda ${ }^{\circledR}$, São Paulo, Brazil) up to $2.0 \mathrm{~mm}$ below the CEJ, resulting in a 0.2 - to $0.3-\mathrm{mm}$-thick wax layer (Figure $1 \mathrm{~b}$ ). The roots were then positioned downward over a perforated wax plate of approximately $4.0-\mathrm{mm}$-thick, so that the 
- New material perspective for endocrown restorations: effects on mechanical performance and fracture behavior

Table 1. Restorative materials used in the present study with their respective code, shade (if appropriate), lot number, and composition information.

\begin{tabular}{|c|c|c|}
\hline Material (Code) & Manufacturer (shade, lot no.) & Composition \\
\hline Filtek $^{\text {TM }}$ Z350 XT (Z350) & 3M ESPE, St. Paul, MN, USA (A2B, 1535700493) & $\begin{array}{l}\text { Bis-GMA, UDMA, TEGDMA, Bis-EMA, } \\
\text { zircônia and silica nanoparticles (78.5 } \\
\text { wt\%/59.5 vol\%) }\end{array}$ \\
\hline $\begin{array}{l}\text { Adper }^{\mathrm{TM}} \text { Scotchbond }{ }^{\mathrm{TM}} \text { Multi-Purpose } \\
\text { Adhesive (SBMP) }\end{array}$ & 3M ESPE, St. Paul, MN, USA (1516300370) & Bond: Bis-GMA, HEMA, photoinitiator \\
\hline $\begin{array}{l}\text { Scotchbond }{ }^{T M} \text { Universal Adhesive } \\
\text { (SBU) }\end{array}$ & 3M ESPE, St. Paul, MN, USA (579965) & $\begin{array}{c}\text { 10-MDP phosphate monomer, } \\
\text { Vitrebond copolymer, HEMA, Bis-GMA, } \\
\text { dimethacrylate resins, filler, silane, initiators, } \\
\text { ethanol, water }\end{array}$ \\
\hline $\begin{array}{l}\text { Filtek }^{\mathrm{TM}} \text { One Bulk Fill Restorative } \\
\text { (Bulk Fill) }\end{array}$ & 3M ESPE, St. Paul, MN, USA (1521500378) & $\begin{array}{l}\text { AFM, AUDMA, UDMA, 1,12-dodecane- } \\
\text { DMA, ytterbium trifluoride, zirconia, silica } \\
\text { (76.5 wt\%/58.5 vol\%) }\end{array}$ \\
\hline
\end{tabular}

10-MDP: 10-methacryloyloxi-decyl-dihydrogen-phosphate; Bis-EMA: bisphenol-A polyethylene glycol diether dimethacrylate; Bis-GMA: bisphenol-A diglycidyl ether dimethacrylate; HEMA: 2-hydroxiethyl methacrylate; TEGDMA, triethylene glycol dimethacrylate; AFM: dynamic stress-relieving monomer; UDMA: urethane dimethacrylate.

alveolar bone simulation was prepared at $2.0 \mathrm{~mm}$ below the CEJ (Figure 1c). One plastic cylinder with a diameter of $25.0 \mathrm{~mm}$ was positioned around each root and fixed over the wax plate, followed by the acrylic resin manipulation according to the manufacturers' instructions and consequent insertion in the cylinder (Figure 1c). After resin polymerization, the roots were removed from the cylinder, and the wax found over each root surface and into each resin cylinder was properly removed. The polyether impression material was manipulated according to the manufacturer's instructions and placed in the resin cylinder, and the roots were reinserted into the cylinder (Figure 1d); any excess impression material was removed using a scalpel blade. ${ }^{23}$

\section{Endocrown preparation and bonding procedure}

Before each endocrown preparation, the largest root canal (distal) was unsealed up to a depth of $2.0 \mathrm{~mm}$, whereas any other root canal (mesial ones) was unsealed by only a depth of $1.0 \mathrm{~mm}$, to take advantage of the saddle-like anatomy of the pulp chamber.

For the groups prepared using resin-based materials, a water-soluble gel (KY; Johnson \& Johnson, São José dos Campos, Brazil) was applied into the pulp chamber for isolation purpose and before insertion of any material increment. The endocrowns were fabricated using the impression of the coronal portion of each tooth as a guide (Figure 1a), thereby facilitating the restoration of the tooth to its original anatomical shape. Each resin increment was placed and modeled individually, followed by light-activation for $20 \mathrm{~s}$ using a light-emitting diode (LED) curing unit (Radii ${ }^{\circledR}$; SDI, Bayswater, VIC, Australia). After completion of the restoration, the tooth was removed from the cavity, placed again, and tested using a probe for fitting observation. The fabrication protocol was different for each group tested; for the Z350 group, the endocrowns were prepared by placing up to 2.0 -mm-thick increments of conventional resin composite; for the Z350+SBMP and Z350+SBU groups, the endocrowns were prepared by placing up to 2.0-mm-thick increments of conventional resin composite, which were modeled using resin adhesives (SBMP or SBU) as the modeler liquid (briefly, after the placement of the first composite increment, a disposable brush was wiped with SBMP or SBU and applied over that increment, thus linking the prior increment with the next one; the adhesives were not directly light-activated), ${ }_{i}^{18,19,24}$ finally, for the Bulk Fill group, the endocrowns were prepared by placing up to 5.0-mm-thick increments of the bulk composite. Each resin increment was light-activated with the LED for $20 \mathrm{~s}$, under a constant irradiance of $900 \mathrm{~mW} / \mathrm{cm}^{2}$.

For the e.max group, the pulp chamber and the root canal entrances of each tooth were shaped with an impression material (Futura AD), and the impression was sent to a prosthetic laboratory for endocrown preparation using IPS e.max Press (Ivoclar Vivadent), which was pressed using the injection 

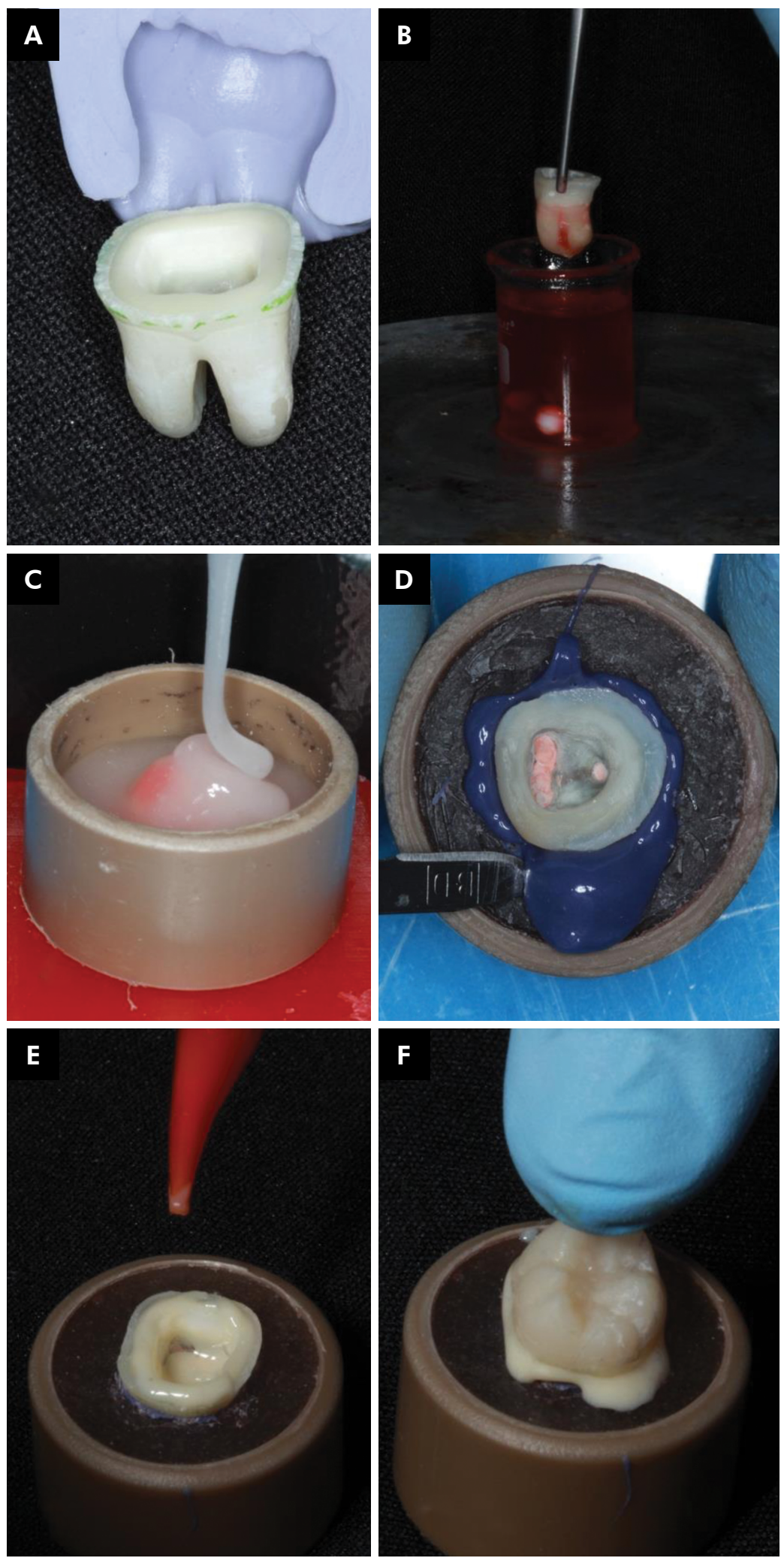

Figure 1. Brief protocol used to prepare the teeth samples; impression of the crown portion of each tooth before crown/root separation (a); wax application on each root surface at $2.0 \mathrm{~mm}$ below the cementoenamel junction (b); alveolus simulation made with acrylic resin (c); periodontal ligament simulation made with polyether impression (d); endocrown cementation using self-adhesive resin cement and Centrix ${ }^{\circledR}$ syringe (e); and pressure of the restoration for 6 min before light-activation ( $f$ ). 
technique according to the manufacturer's materials and instructions. Before bonding, the inner face of the glassy endocrowns was acid-etched with hydrofluoric acid for $20 \mathrm{~s}$, followed by rinsing with distilled water and silane application.

All endocrowns were then luted to the teeth using a self-adhesive resin cement (Rely-X ${ }^{\mathrm{TM}} \mathrm{U} 200 ; 3 \mathrm{M}$ ESPE), following the manufacturers' instructions. Briefly, a Centrix ${ }^{\circledR}$ syringe (DFL) was used to insert the luting cement (Figure 1e), and pressure was applied by holding the restoration in position for 6 min (Figure 1f). Excess material was removed, and light-activation was performed for a total of $200 \mathrm{~s}$ (i.e., $40 \mathrm{~s}$ in each restoration face).

\section{Fatigue test}

All teeth investigated in this study (sound or restored) were submitted to fatigue testing, which was performed using a piston ( $6 \mathrm{~mm}$ in diameter) in a pneumatic chewing simulator (Biocycle V2; Biopdi, São Carlos, Brazil). Each sample (plastic cylinder plus tooth) was positioned in a metal base in a tank filled with distilled water $\left(37^{\circ} \mathrm{C}\right)$, forming a $90^{\circ}$ angle between the horizontal plane and the piston under the following regimen: a load of $125 \mathrm{~N}$ at a frequency of $4 \mathrm{~Hz}$. The piston touched the internal inclines of the buccal and lingual cusps, and each load cycle consisted of the indenter coming into contact with the specimens, loading to a maximum, holding for $0.125 \mathrm{~s}$, and completely unloading for $0.125 \mathrm{~s}$. A total of $1,200,000$ cycles were performed for fatigue testing. Before simulating the chewing cycles, the equipment was calibrated with the pressure necessary to achieve appropriate force. Chipping of the restorative material (resin, ceramic), cracks, catastrophic fracture of the restoration, and de-bonding of the crowns were considered as failures; if none of these was observed, the specimens continued to be subjected to fatigue test until the test was complete. ${ }^{25}$

\section{Fracture test, work-of-fracture $\left(\mathrm{W}_{\mathrm{f}}\right)$, and failure analysis}

The fracture test was performed in a Universal Testing Machine (EMIC DL500; EMIC, São José dos Pinhais, Brazil). All samples were mounted on a metal base, and the stainless steel round load cell was applied perpendicular (axial loading) to the occlusal plane, at the central fissure. ${ }^{26}$ The maximum force $(\mathrm{N})$ required to produce a fracture was recorded. Load-displacement curves obtained during fracture testing were used to quantify the $\mathrm{W}_{\mathrm{f}}$ of the restored and sound teeth, which was determined by dividing the area under the load-displacement curve by the cross-sectional area of specimens (i.e., width $\times$ thickness). The data were expressed in $\mathrm{J} / \mathrm{m}^{2} .{ }^{27}$ All data (load-to-fracture and work-of-fracture) were statistically analyzed by SigmaPlot version 12 (Systat Software Inc., San Jose, USA) and one-way analysis of variance, with a $5 \%$ level of significance.

Failure pattern characteristics of each specimen were defined by observation under a stereoscopic loupe at $40 \times$ magnification. ${ }^{22}$ Digital photos were prepared from the samples, and failure types were classified as follows: Type I - cohesive failure in the endocrown material; Type II - adhesive failure between the endocrown and dentin; Type III cohesive failure in the enamel and dentin; and Type IV - fracture extending to the root. Failures above the CEJ were considered as "repairable," and those below the CEJ extending to the root were classified as "irrepairable." 26

\section{Results}

The load-to-fracture mean values obtained in this study, which ranged from $1979.2 \mathrm{~N}$ (E.max group) to 2681.4 N (Bulk Fill group), are shown in Table 2. The endocrowns exhibited similar load-to-fracture to the sound teeth (negative control), with no difference among each other $(p=0.224)$. Regarding the analysis of fracture results, which are also shown in Table 2, the groups showed no significant difference among each other $(p=0.681)$, regardless of the restorative material used. The work-of-fracture mean values ranged from $12.0 \mathrm{~J} / \mathrm{m}^{2}$ (Z350 group) to $13.8 \mathrm{~J} / \mathrm{m}^{2}$ (sound tooth group).

Load $\times$ deflection curves (representative of the mean values) obtained during the fracture test are depicted in Figure 2. The endocrowns prepared with the modeler liquid (Z350+SBMP or Z350+SBU) supported apparent greater deflection than the 
Table 2. Mean and standard deviation (SD) values for the fracture strength and work of fracture of groups investigated.

\begin{tabular}{lcc}
\hline Groups & $\begin{array}{c}\text { Fracture strength* } \\
(\mathrm{n})\end{array}$ & $\begin{array}{c}\text { Work of fracture* } \\
\left(\mathrm{J} / \mathrm{m}^{2}\right)\end{array}$ \\
\hline Sound tooth (- control) & $2246.8(557.7)$ & $13.8(1.6)$ \\
Z350 & $2514.7(569.1)$ & $12.0(2.3)$ \\
Z350+SBMP & $2042.6(678.4)$ & $13.4(2.5)$ \\
Z350+SBU & $2346.7(632.7)$ & $12.6(2.4)$ \\
Bulk Fill & $2681.4(521.6)$ & $12.2(1.8)$ \\
E.max (+ control) & $1979.2(795.8)$ & $12.8(1.5)$ \\
\hline
\end{tabular}

*The groups have not differed statistically among each other (One Way ANOVA; $p>0.05$ ). other endocrowns and the sound teeth. The E.max endocrowns appeared to present less ability to support stress, failing earlier and upon lower load.

Table 3 presents the results for each failure mode obtained in the study. All groups produced at least one fracture extending to the root (Type IV). Sound teeth fractured primarily within the cohesiveness of the enamel and dentin (Type III), corresponding to approximately $86 \%$ of repairable fractures. The endocrowns prepared with the modeler liquid

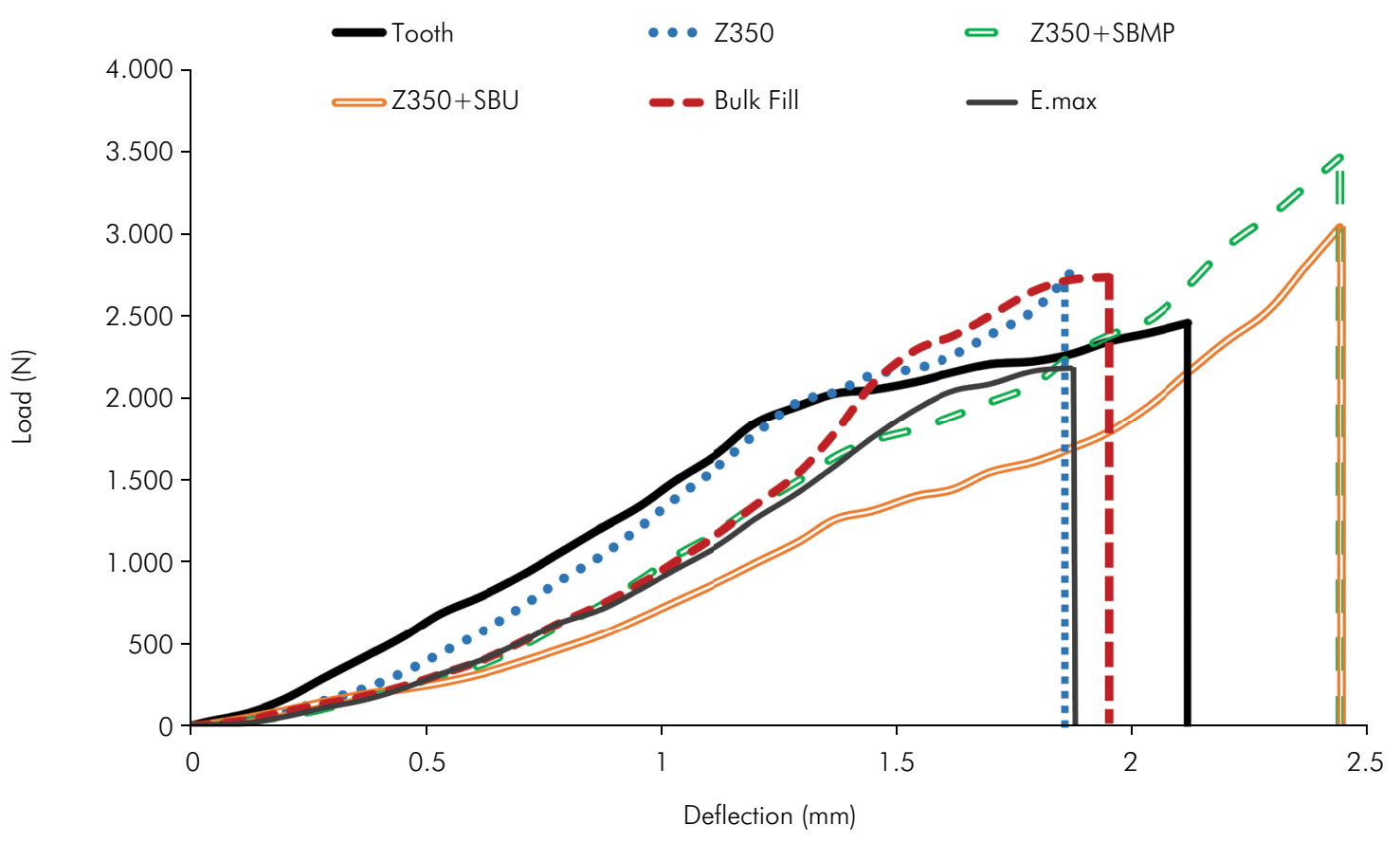

Figure 2. Load-deflection curves obtained from the average results of the endocrowns tested in this study. Z350: conventional resin composite; Z350 + SBMP: conventional composite modeled with resin adhesive (SBMP); Z350+SBU: conventional composite modeled with resin adhesive (SBU); Bulk Fill: bulk fill resin composite; and E.max: IPS Empress lithium disilicate.

Table 3. Results for the failure mode obtained for all samples tested in the study, which were ranked according to their condition for repair, in percentage.

\begin{tabular}{|c|c|c|c|c|c|c|}
\hline \multirow{2}{*}{ Groups } & \multicolumn{4}{|c|}{ Failure mode $(n=7)$} & \multicolumn{2}{|c|}{ Condition for repair (\%) } \\
\hline & Type 1 & Type 2 & Type 3 & Type 4 & Repairable & Irrepairable \\
\hline Sound tooth & 0 & 0 & 6 & 1 & 85.7 & 14.3 \\
\hline Z350 & 1 & 3 & 0 & 3 & 57.1 & 42.9 \\
\hline$Z 350+$ SBMP & 4 & 2 & 0 & 1 & 85.7 & 14.3 \\
\hline$Z 350+S B U$ & 5 & 0 & 0 & 2 & 71.4 & 28.6 \\
\hline Bulk Fill & 4 & 1 & 0 & 2 & 71.4 & 28.6 \\
\hline E.max & 2 & 0 & 0 & 5 & 28.6 & 71.4 \\
\hline
\end{tabular}

SBMP: Scotchbond ${ }^{T M}$ Multi-Purpose ${ }^{T M}$ Adhesive; SBU: Scotchbond ${ }^{T M}$ Universal Adhesive; E.max: IPS emax lithium disilicate ceramic. 

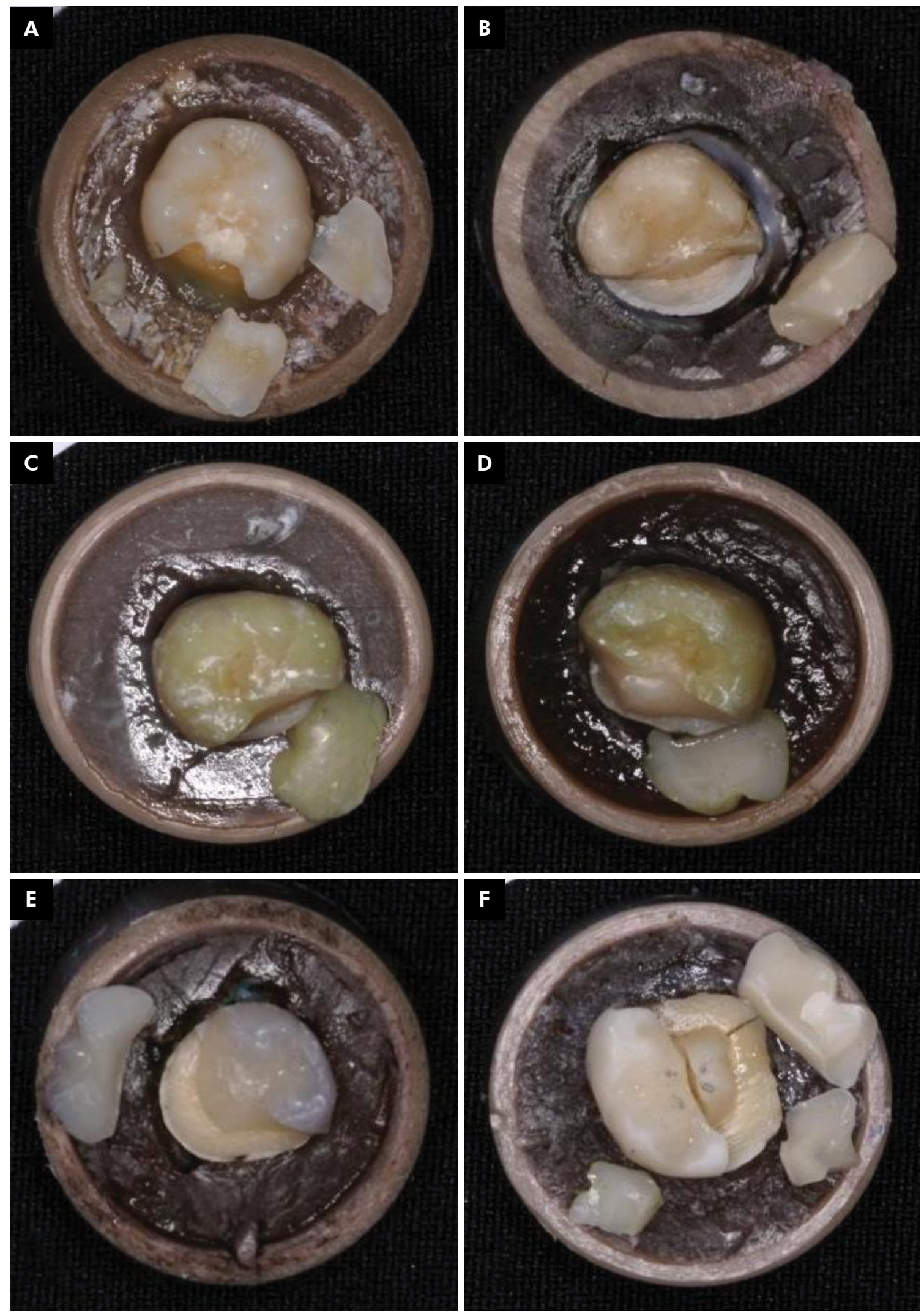

Figure 3. Representative images of the most frequent failure mode observed for all groups tested in the study. 
(SBMP or SBU) or the bulk fill composite resulted in a greater number of repairable fractures than the endocrowns fabricated using conventional composite or glass ceramic. The Z350+SBMP group resulted in the least harsh fractures ( $86 \%$ of repairability), in contrast to the endocrowns prepared using Z350 only, which exhibited equilibrium between repairable and irrepairable fractures (nearly 57\% $\times 43 \%$, respectively). The more aggressive failures were observed in the E.max group, with most of the fractures (approximately 71\%) extending to the root. Figure 3 presents a representative image of the most frequent failure mode found for each group tested in this study.

\section{Discussion}

In general, endocrowns are prepared using glass-ceramics. The primary disadvantage of this restorative material compared with other systems (e.g., conventional crowns combined with intraradicular posts) is that glass-ceramics are brittle, showing on the one hand high stiffness but on the other hand little elastic behavior, ${ }^{28}$ which thereby favors the occurrence of catastrophic failures such as fractures extending to the root (Figure 3f). This fact corroborates our findings, since the E.max group exhibited a high frequency of Type IV failures. Despite the similar load-to-fracture values exhibited by all the investigated groups, the E.max group resulted in a greater amount (approximately 71\%) of irrepairable failures than the other groups, probably due to the resin nature of the latter, which allows better stress distribution during fatigue and fracture testing, ${ }^{28}$ and consequently, the occurrence of less aggressive fractures (mostly Type I failure mode). Hence, it appears that the use of more compliant materials would produce a better biomechanical match between restoration and tooth.

Recently, Lise et al. ${ }^{29}$ analyzed the effect of CAD/CAM material type on the load-to-failure of nonvital premolars and found that resin composite appeared to be more favorable than lithium disilicate glass-ceramic as the crown material. In this study, a total of four groups was designed using resin-based materials: conventional resin composite combined or not with resin adhesives as the modeler liquid or the bulk fill resin composite. According to Münchow et al., ${ }^{18}$ the use of resin adhesives as the modeler liquid of resin composites improved cohesiveness within the bulk of the material, reducing hydrolysis after 6 months of water storage. In fact, teeth restored using modeler liquid (Z350+SBMP or Z350+SBU) displayed a greater ability to support stress (i.e., greater deflection), as shown in Figure 2. This finding suggests that the presence of the less viscous resin adhesives within the bulk of the endocrown facilitated stress distribution, thereby prolonging the load-to-fracture of the restoration. In addition, it may be considered that the presence of resin adhesives may have contributed to a greater elastic behavior, since they are generally unfilled or consist of low amounts of fillers, unlike the highly filled resin composites. Finally, it is noteworthy that the endocrowns prepared using resin adhesives did not result in the greatest load-to-fracture and work-of-fracture results in this study; however, they certainly demonstrated a different pattern of fracture, with the occurrence of less aggressive failure modes (mostly Type I), suggesting their more compliant behavior than other restoratives tested. Not less important, the presence of resin adhesives within the bulk of the endocrowns could also have diminished the occurrence of defects (e.g., air voids, unpacked zones), thus enhancing the cohesiveness of the restorative system and its resistance to degradation during fatigue testing.

Regarding the use of conventional composite only (Z350) to fabricate the endocrowns, this group demonstrated one of the highest load-to-fracture mean values of the study $(2514.7 \mathrm{~N})$, but the lowest work-of-fracture value $\left(12.0 \mathrm{~J} / \mathrm{m}^{2}\right)$. Work-of-fracture is a mechanical property that is commonly used to predict the interfacial fracture toughness of materials, involving the ability of a material containing a crack to resist fracture..$^{30}$ In simple words, work-of-fracture corresponds to the total energy required to grow a thin crack, and restorations with greater work-of-fracture would probably resist longer and more intensively to fatigue and fracture. Once again, all the groups in the present study showed similar work-of-fracture results, although the greatest values were observed for the sound tooth $\left(13.8 \mathrm{~J} / \mathrm{m}^{2}\right)$ and Z350+SBMP $\left(13.4 \mathrm{~J} / \mathrm{m}^{2}\right)$ groups. It can be inferred that a sound 
tooth possesses a work-of-fracture behavior that may not be completely restored using current restorative materials, although a better match may be obtained by combining the conventional resin composite tested here (Z350) and the moderately hydrophobic resin adhesive (SBMP) used as the modeler liquid.

To the best of our knowledge, this is the first study to fabricate endocrowns using a new-generation bulk fill resin composite. Although there were no statistical differences, the endocrowns prepared using the bulk fill composite exhibited the greatest load-to-fracture mean values of the study $(2681.4 \mathrm{~N})$. One possible explanation is that bulk fill composites are generally composed of a lower amount of fillers than that of conventional composites (Filtek ${ }^{\mathrm{TM}}$ Bulk Fill possesses $42.5 \mathrm{vol} \%$ of fillers vs. $59.5 \mathrm{vol} \%$ of Filtek $^{\mathrm{TM}}$ Z350 XT; Table 1), which may have influenced modulus development within the restoration, with the former exhibiting a more compliant behavior than the latter. ${ }^{1,31}$ Not less important, bulk fill composites may also generate less amount of polymerization stress when compared with conventional formulations, ${ }^{21}$ positively influencing the restoration resistance to fatigue. Remarkably, none of the endocrowns failed during fatigue testing, indicating their feasibility to the rehabilitation of severely damaged nonvital teeth.

Regarding the absence of significant statistical differences among the groups tested in our study, there could possibly be two explanations. First, axial loading was used to test the load-to-fracture of restorations. According to Gresnigt et al., ${ }^{26}$ axial loading may overestimate the maximum force tolerated by the restorative system, resulting in similar behavior among the groups. Second, some groups failed at the tooth-restoration interface (i.e., Type II failure mode), indicating that failure occurred due to a bonding-related reason, and not due to a weakness or a limitation of the material system used to fabricate the endocrown. According to a recent prospective clinical study, ${ }^{5}$ the use of self-adhesive resin cement, as used here, is a feasible alternative for dental cementation purposes, resulting in high and adequate survival rates. However, the occurrence of some Type II failures suggests that the luting procedure influences the effectiveness of endocrown restorations, with proper bonding being paramount to extend the mechanical performance and longevity of the restoration during oral function.

Despite the restorative system used, when a fracture occurs, it is always desirable that a repairable fracture occurs rather than an aggressive and irrepairable fracture. Fractures extending to the root are generally difficult to restore as there might be a need for surgical procedures, thus prolonging the treatment and making it more complex and more expensive to the patient. ${ }^{32}$ In the present study, all groups exhibited at least one Type IV failure. Interestingly, endocrowns prepared using Z350 and SBMP displayed the most similar fracture pattern compared with the sound tooth group, exhibiting only one Type IV failure. Similarly, endocrowns prepared using modeler liquid or bulk fill composite also exhibited a satisfactory restorative combination with respect to repairability of fractures. It appears that the presence of unfilled or partially filled resin adhesives in between the layers of conventional composite or the use of bulk fill composite allows an adequate mechanical behavior for endocrown restorations, making them more resistant to aggressive fractures than glassceramic endocrowns and endocrowns fabricated using conventional composite only.

Finally, it is worth mentioning that the present findings may not be directly translated to the clinic, since the experimental conditions were composed of static axial loading. According to Gresnigt et al., ${ }^{26}$ axial loading produces greater forces than lateral loading, generally above the mean masticatory forces in humans (e.g., approximately 600-900 N for females and males, respectively). ${ }^{33,34}$ In the present study, we tested the endocrowns using only static axial loading, overestimating the load-to-fracture performance of the restoration. However, we must emphasize that the purpose of our study was to investigate the mechanical performance and the fracture behavior of endocrowns prepared using distinct restorative materials; hence, axial loading would be more advisable. Gresnigt et al. ${ }^{26}$ also demonstrated that axial loading may evaluate more directly the effect of inherent characteristics (e.g., elasticity modulus) of materials on their mechanical behavior rather than lateral loading, which would be more associated with the adhesion effect of the restoration on the bonding outcome. As a result, the 
high load-to-fracture values obtained in the present study are important for understating the mechanics of structurally distinct endocrowns, as demonstrated by our load-to-fracture and work-of-fracture results. On the other hand, addition of lateral loading to a dynamic loading condition would perhaps result in different data of greater clinical relevance, although it was not the major purpose of this in vitro study.

\section{Conclusions}

Considering all the study findings, the endocrowns prepared using resin adhesives as the modeler liquid or using bulk fill resin composite demonstrated similar performance compared with endocrowns fabricated using conventional composite or glass ceramic, at least in terms of the mechanical properties investigated (load-to-fracture and work-of-fracture), thus rejecting the study hypothesis. Notwithstanding, the more compliant and elastic behavior of the former restorations may contribute to the occurrence of less aggressive failure of the restoration. This finding should be considered when choosing the best restorative system to restore severely damaged, nonvital teeth using the endocrown approach.

\section{Acknowledgments}

This study was financed in part by the Coordenação de Aperfeiçoamento de Pessoal de Nível Superior Brasil (CAPES) - Finance Code 001.

The authors thank the BDH/UNOESC for donation of the teeth samples used in this study.

\section{References}

1. Zhu J, Rong Q, Wang X, Gao X. Influence of remaining tooth structure and restorative material type on stress distribution in endodontically treated maxillary premolars: A finite element analysis. J Prosthet Dent. 2017 May; 117(5):646-55. https://doi.org/10.1016/i.prosdent.2016.08.023

2. Roscoe MG, Noritomi PY, Novais VR, Soares CJ. Influence of alveolar bone loss, post type, and ferrule presence on the biomechanical behavior of endodontically treated maxillary canines: strain measurement and stress distribution. J Prosthet Dent. 2013 Aug;110(2):116-26. Available from: 10.1016/S0022-3913(13)60350-9

3. Chun KJ, Lee JY. Comparative study of mechanical properties of dental restorative materials and dental hard tissues in compressive loads. J Dent Biomech. 2014 Oct;5(0):1758736014555246.https://doi.org/10.1177/1758736014555246

4. Güncü MB, Cakan U, Muhtarogullari M, Canay S. Zirconia-based crowns up to 5 years in function: a retrospective clinical study and evaluation of prosthetic restorations and failures. Int J Prosthodont. 2015 Mar-Apr;28(2):152-7. https://doi.org/10.11607/ijp.4168

5. Brondani LP, Pereira-Cenci T, Wandsher VF, Pereira GK, Valandro LF, Bergoli CD. Longevity of metal-ceramic crowns cemented with self-adhesive resin cement: a prospective clinical study. Braz Oral Res. 2017 Apr;31(0):e22. Available from: https://doi.org/10.1590/1807-3107bor-2017.vol31.0022

6. Skupien JA, Cenci MS, Opdam NJ, Kreulen CM, Huysmans MC, Pereira-Cenci T. Crown vs. composite for post-retained restorations: A randomized clinical trial. J Dent. 2016 May;48:34-9. Available from: https://doi.org/10.1016/i.jdent.2016.03.007

7. A Alharbi F, Nathanson D, Morgano SM, Baba NZ. Fracture resistance and failure mode of fatigued endodontically treated teeth restored with fiber-reinforced resin posts and metallic posts in vitro. Dent Traumatol. 2014 Aug;30(4):317-25. https://doi.org/10.1111/edt.12095

8. Zhang H, Cui JW, Lu XL, Wang MQ. Finite element analysis on tooth and periodontal stress under simulated occlusal loads. J Oral Rehabil. 2017 Jul;44(7):526-36. https://doi.org/10.1111/joor.12512

9. Soares CJ, Valdivia AD, Silva GR, Santana FR, Menezes MS. Longitudinal clinical evaluation of post systems: a literature review [pii]. Braz Dent J. 2012;23(2):135-740. Available from: https://doi.org/S0103-64402012000200008

10. Zarow M, Ramirez-Sebastia A, Paolone G, de Ribot Porta J, Mora J, Espona J, et al. A new classification system for the restoration of root filled teeth. Int Endod J. 2017;51(3):318-34: https://doi.org/10.1111/iej.12847

11. Belleflamme MM, Geerts SO, Louwette MM, Grenade CF, Vanheusden AJ, Mainjot AK. No post-no core approach to restore severely damaged posterior teeth: An up to 10-year retrospective study of documented endocrown cases. J Dent. 2017. https://doi.org/S0300-5712(17)30093-3

12. Lander E, Dietschi D. Endocrowns: a clinical report. Quintessence Int. 2008 Feb;39(2):99-106. Available from: https://doi.org/12972

13. Yeh CJ. Fatigue root fracture: a spontaneous root fracture in non-endodontically treated teeth. Br Dent J. 1997 Apr;182(7):261-6. https://doi.org/10.1038/sj.bdj.4809363 
New material perspective for endocrown restorations: effects on mechanical performance and fracture behavior

14. Zarone F, Sorrentino R, Apicella D, Valentino B, Ferrari M, Aversa R, et al. Evaluation of the biomechanical behavior of maxillary central incisors restored by means of endocrowns compared to a natural tooth: a 3D static linear finite elements analysis. Dent Mater. 2006 Nov;22(11):1035-44. Available from: https://doi.org/10.1016/i.dental.2005.11.034

15. Sedrez-Porto JA, Rosa WL, Silva AF, Münchow EA, Pereira-Cenci T. Endocrown restorations: a systematic review and meta-analysis. J Dent. 2016 Sep;52:8-14. https://doi.org/10.1016/i.jdent.2016.07.005

16. Rocca GT, Krejci I. Crown and post-free adhesive restorations for endodontically treated posterior teeth: from direct composite to endocrowns. Eur J Esthet Dent. 2013;8(2):156-79. Available from: https://doi.org/29722

17. Ramírez-Sebastià A, Bortolotto T, Cattani-Lorente M, Giner L, Roig M, Krejci I. Adhesive restoration of anterior endodontically treated teeth: influence of post length on fracture strength. Clin Oral Investig. 2014;18(2):545-54. https://doi.org/10.1007/s00784-013-0978-3

18. Münchow EA, Sedrez-Porto JA, Piva E, Pereira-Cenci T, Cenci MS. Use of dental adhesives as modeler liquid of resin composites. Dent Mater. 2016 Apr;32(4):570-7. https://doi.org/10.1016/i.dental.2016.01.002

19. Sedrez-Porto JA, Münchow EA, Brondani LP, Cenci MS, Pereira-Cenci T. Effects of modeling liquid/resin and polishing on the color change of resin composite. Braz Oral Res. 2016 Aug;30(1):S1806-83242016000100275. https://doi.org/10.1590/1807-3107BOR-2016.vol30.0088

20. Braga RR, Hilton TJ, Ferracane JL. Contraction stress of flowable composite materials and their efficacy as stress-relieving layers. J Am Dent Assoc. 2003 Jun;134(6):721-8. https://doi.org/10.14219/jada.archive.2003.0258

21. El-Damanhoury H, Platt J. Polymerization shrinkage stress kinetics and related properties of bulk-fill resin composites. Oper Dent. 2014 Jul-Aug;39(4):374-82. https://doi.org/10.2341/13-017-L

22. Biacchi GR, Basting RT. Comparison of fracture strength of endocrowns and glass fiber post-retained conventional crowns. Oper Dent. 2012 Mar-Apr;37(2):130-6. https://doi.org/10.2341/11-105-L

23. Soares CJ, Pizi EC, Fonseca RB, Martins LR. Influence of root embedment material and periodontal ligament simulation on fracture resistance tests. Braz Oral Res. 2005 Jan-Mar;19(1):11-6. https://doi.org/10.1590/S1806-83242005000100003

24. Sedrez-Porto JA, Münchow EA, Cenci MS, Pereira-Cenci T. Translucency and color stability of resin composite and dental adhesives as modeling liquids - A one-year evaluation. Braz Oral Res. 2017 Jul;31(0):e54. https://doi.org/10.1590/1807-3107bor-2017.vol31.0054

25. Ramos GF, Monteiro EB, Bottino MA, Zhang Y, Melo RM. Failure probability of three designs of zirconia crowns. Int J Periodontics Restorative Dent. 2015 Nov-Dec;35(6):843-9. https://doi.org/10.11607/prd.2448

26. Gresnigt MM, Özcan M, Houten ML, Schipper L, Cune MS. Fracture strength, failure type and Weibull characteristics of lithium disilicate and multiphase resin composite endocrowns under axial and lateral forces. Dent Mater. 2016 May;32(5):607-14. https://doi.org/10.1016/i.dental.2016.01.004

27. Borges AL, Münchow EA, Souza ACO, Yoshida T, Vallittu PK, Bottino MC. Effect of random/aligned nylon-6/MWCNT fibers on dental resin composite reinforcement. J Mech Behav Biomed Mater. 2015 Aug;48:134-44. https://doi.org/10.1016/i.jmbbm.2015.03.019

28. Belli R, Geinzer E, Muschweck A, Petschelt A, Lohbaver U. Mechanical fatigue degradation of ceramics versus resin composites for dental restorations. Dent Mater. 2014 Apr;30(4):424-32. https://doi.org/10.1016/i.dental.2014.01.003

29. Lise DP, Van Ende A, De Munck J, Umeda Suzuki TY, Vieira LCC, Van Meerbeek B. Biomechanical behavior of endodontically treated premolars using different preparation designs and CAD/CAM materials. J Dent. 2017 Apr;59:54-61. https://doi.org/10.1016/i.jdent.2017.02.007

30. Mayer G. New toughening concepts for ceramic composites from rigid natural materials. J Mech Behav Biomed Mater. 2011 Jul;4(5):670-81. https://doi.org/10.1016/i.jmbbm.2010.08.001

31. Zorzin J, Maier E, Harre S, Fey T, Belli R, Lohbaver U, et al. Bulk-fill resin composites: polymerization properties and extended light curing. Dent Mater. 2015 Mar;31(3):293-301. https://doi.org/10.1016/i.dental.2014.12.010

32. Stojanac IL, Bajkin BV, Premovic MT, Ramic BD, Petrovic LM. Multidisciplinary treatment of complicated crown-root fractures: A case study. Oper Dent. 2016 Nov/Dec;41(6):e168-73. https://doi.org/10.2341/15-080-T

33. Cosme DC, Baldisserotto SM, Canabarro SA, Shinkai RS. Bruxism and voluntary maximal bite force in young dentate adults. Int J Prosthodont. 2005 Jul-Aug;18(4):328-32.

34. Varga S, Spali S, Lapter Varga M, Anic Milosevic S, Mestrovic S, Slaj M. Maximum voluntary molar bite force in subjects with normal occlusion. Eur J Orthod. 2011 Aug;33(4):427-33. https://doi.org/10.1093/ejo/ciq097 